\title{
$\beta$-Catenin Regulates Acetylcholine Receptor Clustering in Muscle Cells through Interaction with Rapsyn
}

\author{
Bin Zhang, ${ }^{1 \star}$ Shiwen Luo, ${ }^{1 \star}$ Xian-Ping Dong, ${ }^{1 \star}$ Xian Zhang, ${ }^{2}$ Chunming Liu, ${ }^{3}$ Zhenge Luo, ${ }^{2}$ Wen-Cheng Xiong, ${ }^{1}$ and \\ Lin $\mathrm{Mei}^{1}$ \\ ${ }^{1}$ Program of Developmental Neurobiology and Department of Neurology, Institute of Molecular Medicine and Genetics, Medical College of Georgia, \\ Augusta, Georgia 30912, ${ }^{2}$ Institute of Neuroscience, Chinese Academy of Sciences, Shanghai 200031, China, and ${ }^{3}$ Sealy Center for Cancer Cell Biology, \\ University of Texas Medical Branch, Galveston, Texas 77555
}

\begin{abstract}
Agrin is believed to be a factor used by motoneurons to direct acetylcholine receptor (AChR) clustering at the neuromuscular junction. However, exactly how agrin mediates this effect remains unclear. Here we demonstrate that the $\beta$-catenin interacts with rapsyn, a molecule key for AChR clustering. Agrin stimulation increases the association of $\beta$-catenin with surface AChRs. Suppression of $\beta$-catenin expression inhibited agrin-induced AChR clustering, suggesting a necessary role of $\beta$-catenin in this event. The $\beta$-catenin action did not appear to require the function of T-cell factors (TCFs), suggesting a mechanism independent of TCF-mediated transcription. In contrast, prevention of $\beta$-catenin from interacting with $\alpha$-catenin attenuated agrin-induced AChR clustering. These results suggest that $\beta$-catenin may serve as a link between AChRs and $\alpha$-catenin-associated cytoskeleton, revealing a novel function of $\beta$-catenin in synaptogenesis.
\end{abstract}

Key words: $\beta$-catenin; rapsyn; interaction; AChR; cluster; $\alpha$-catenin

\section{Introduction}

The neuromuscular junction (NMJ) is a peripheral cholinergic synapse that conveys signals from motoneurons to muscle cells. It has served as an informative model of synaptogenesis because of its simplicity and easy accessibility (Sanes and Lichtman, 1999). During development, acetylcholine receptors (AChRs) aggregate at the postjunctional membrane in response to factors released from motoneurons including agrin (McMahan et al., 1992; Sanes and Lichtman, 1999). Agrin activates the muscle-specific tyrosine kinase (MuSK) and induces AChR clusters in cultured muscle cells. Mice deficient in agrin or MuSK do not form the NMJ (DeChiara et al., 1996; Gautam et al., 1996). A third protein that is essential for NMJ formation is rapsyn, an intracellular molecule (Burden et al., 1983; LaRochelle and Froehner, 1986; Gautam et al., 1995; Moransard et al., 2003). This protein is associated with AChRs and is thought to link AChRs to actin cytoskeleton (Dai et al., 2000). Interference of actin cytoskeleton attenuates AChR clustering (Bloch, 1986; Dai et al., 2000). However, how rapsyn couples the AChR to the actin cytoskeleton remains unclear. In this study, we demonstrate that rapsyn interacts with $\beta$-catenin. Suppression of $\beta$-catenin expression or inhibition of its interaction with $\alpha$-catenin inhibited agrin-induced AChR

Received 0ct. 27, 2006; revised Feb. 15, 2007; accepted March 6, 2007.

This work was supported in part by grants from the National Institutes of Health (L.M., W.-C.X.) and the Muscular Dystrophy Association (L.M.). We thank Drs. Richard Rotundo, Xian Yu, Xi He, and Christian Fuhrer for providing reagents. We are grateful to Dr. Zach Hall for sharing unpublished results and to members of the Mei laboratory for discussion. We declare no competing interests.

*B.Z., S.L., and X.-P.D. contributed equally to this work.

Correspondence should be addressed to Dr. Lin Mei, Program of Developmental Neurobiology, Institute of Molecular Medicine and Genetics, Medical College of Georgia, Augusta, GA 30912. E-mail: Imei@mcg.edu.

DOI:10.1523/JNEUROSCI.4691-06.2007

Copyright $\odot 2007$ Society for Neuroscience $\quad$ 0270-6474/07/273968-06\$15.00/0 clustering. Our results identify a role of $\beta$-catenin in regulating AChR cluster formation by agrin.

\section{Materials and Methods}

DNA constructs and antibodies. Wnt, DKK1, and Fz-Fc constructs were described previously (Semenov et al., 2001; Zhang et al., 2006). Stabilized $\beta$-catenin $\left(\beta\right.$-cat $\left.{ }^{*}\right)$ was a gift from Dr. X. Yu (Institute of Neuroscience, Chinese Academy of Sciences, Shanghai, China) (Yu and Malenka, 2003). $\beta$-Catenin-AA was generated by using the Quick Change mutagenesis kit (Stratagene, La Jolla, CA). $\beta$-Catenin short hairpin RNA (shRNA) constructs were generated by using the BLOCK-iT U6 RNAi Entry Vector kit (Invitrogen, Carlsbad, CA). The sequences of shRNA primers were as follows: for shRNA- $\beta$-cat811, $5^{\prime}$-CACCGCACCATGCAGAATACAAATGCGAACATTTGTATTCTGCATGGTGC (sense) and $5^{\prime}$-AAAAGCACCATGCAGAATACAAATGTTCGCATTTGTATTCTGCATGGTGC (antisense); for shRNA- $\beta$-cat1196, $5^{\prime}$-CACCGGACCTACACTTATGAGAAGCCGAAGCTTCTCATAAGTGTAGGTCC (sense) and 5' -AAAAGGACCTACACTTATGAGAAGCTTCGGCTTCTCATAAGTGTAGGTCC (antisense); for shRNA- $\beta$-cat2405, 5'-CACCGGACCCTATGATGGAGCATGACGAATCATGCTCCATCATAGGGTCC (sense) and 5'-AAAAGGACCCTATGATGGAGCATGATTCGTCATGCTCCATCATAGGGTCC (antisense). The numbers in the names of shRNA constructs indicate the targeting nucleotide sequences. To generate refractory $\beta$-catenin expression vectors, sitedirected mutations were made in green fluorescent protein (GFP) $-\beta$ $\mathrm{cat}^{\star}$ on corresponding nucleotides underlined in the sense primers described above. For RF811, CACC were mutated to TACT; for RF1196, TTAT were mutated to GTAC. These mutations were silent and thus did not change the amino acid sequences of $\beta$-catenin. Antibodies were from the following companies: $\beta$-catenin (catalog \#610154; BD Biosciences, San Jose, CA), $\alpha$-catenin (catalog \#610194; BD Biosciences), GFP (catalog \#TP401; Torrey Pines Biolabs, Houston, TX), Flag M2 (catalog \#F3165; Sigma, St. Louis, MO), HA 12CA5 (catalog \#ab16918; Abcam, Cambridge, MA), Fc (catalog \#209-005-098; Jackson ImmunoResearch, West Grove, PA), glyceraldehyde-3-phosphate dehydrogenase (catalog 

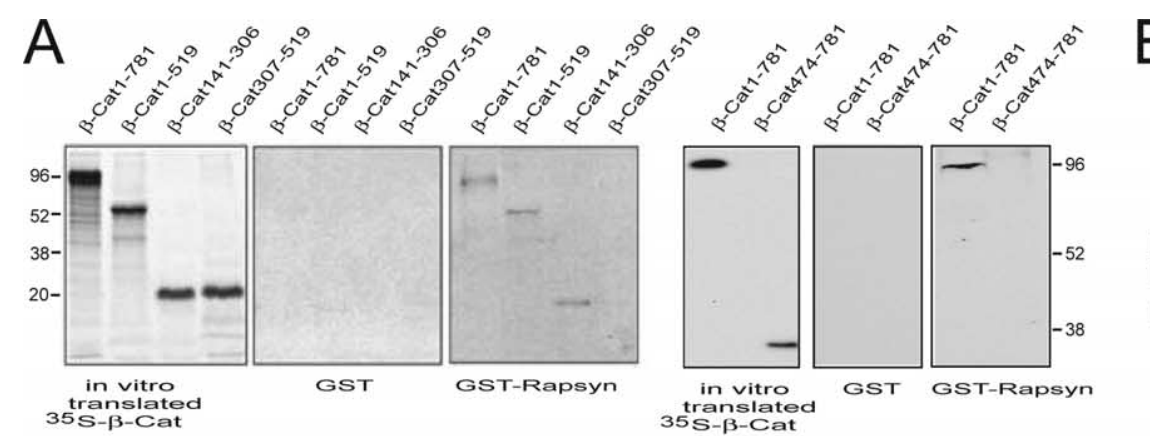

B
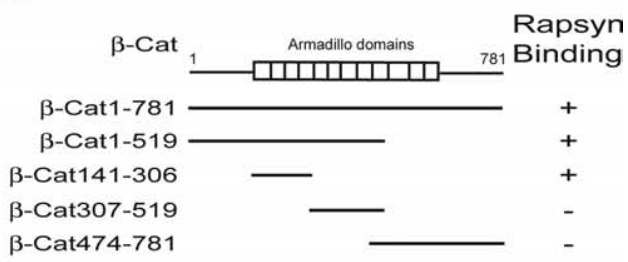

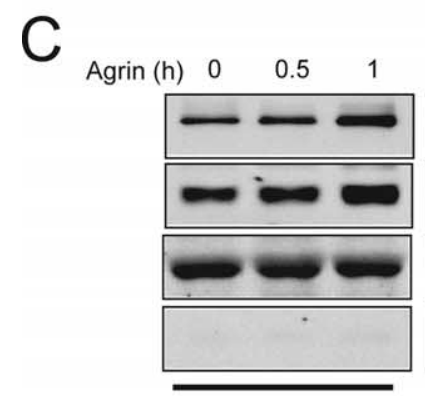

PD: Biotin- $\alpha$ BTX

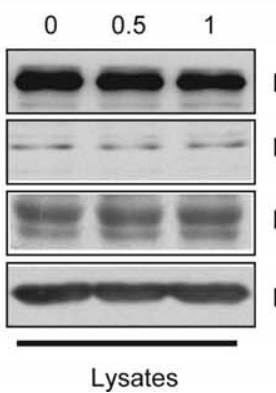

IB: $\beta-$ Cat

IB: Rapsyn

IB: $A C h R \alpha$

IB: GAPDH

Lysates

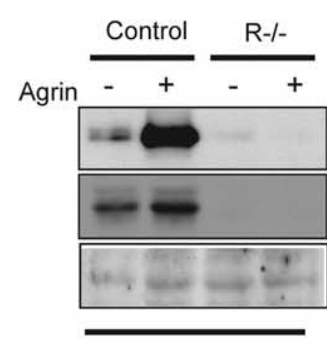

PD: Biotin- $\alpha$ BTX

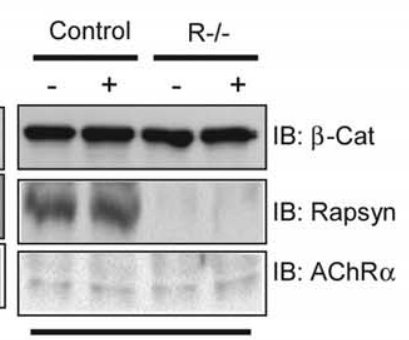

Lysates

Figure 1. $\beta$-Catenin associates with the AChR complex through rapsyn. $\boldsymbol{A}$, Direct interaction of $\beta$-catenin with rapsyn. $\left.{ }^{35} \mathrm{~S}\right]$-labeled $\beta$-catenin proteins were incubated with GST alone or GST-rapsyn immobilized on beads. Bound $\left[{ }^{35} \mathrm{~S}\right]-\beta$-catenin proteins were visualized by autoradiogram. Molecular weight markers are in kilodaltons. $\boldsymbol{B}$, Schematic diagram of $\beta$-catenin constructs and binding activity to rapsyn. C, Association of $\beta$-catenin with surface AChR in muscle cells. Live myotubes, treated with agrin for indicated times, were incubated with biotin- $\alpha$ BTX to label surface AChR. Lysates were incubated with streptavidin-coupled agarose beads, and bead-associated proteins were subjected to immunoblotting with antibodies against AChR $\alpha$, $\beta$-catenin, and rapsyn. Lysates (5\% of input) were blotted to indicate equal amounts of inputs. $D, \beta$-Catenin association with $A C h R$ requires rapsyn. Control or rapsyn mutant ( $R-/-$ ) myotubes were stimulated without or with agrin for $12 \mathrm{~h}$. Proteins associated with surface AChRs were isolated as in Cand probed with indicated antibodies. Lysates (5\% of input) were blotted to indicate equal amounts of inputs. PD, Pull down; IB, immunoblotting; GAPDH, glyceraldehyde-3-phosphate dehydrogenase.

\#MAB374; Millipore, Temecula, CA), and AChR $\alpha$-subunit (AChR $\alpha$; mAb35; gift from Dr. R. Rotundo, University of Miami, Miami, FL). Anti-rapsyn antibody was generated in rabbits with glutathione $S$ transferase (GST)-rapsyn.

Cell culture and transfection. $\mathrm{C} 2 \mathrm{C} 12$ cells were maintained as undifferentiated myoblasts in DMEM with high glucose supplemented with $20 \%$ fetal bovine serum, $0.5 \%$ chicken embryo extract, and $2 \mathrm{~mm}$ L-glutamine. Fusion of myoblasts into myotubes was induced by culturing in the differentiation medium (DM): DMEM supplemented with 5\% horse serum and 2 mM L-glutamine. Rapsyn ${ }^{-1-}$ (clone 11-7) and control (clone 1210) muscle cells were generated from rapsyn null mutant mice (Apel et al., 1997) and, as gift from Dr. C. Fuhrer, were cultured as described previously (Fuhrer et al., 1999). A concentration of $10 \mathrm{ng} / \mathrm{ml}$ agrin was used for stimulation for $16 \mathrm{~h}$ unless indicated otherwise. C2C12 myoblasts were transfected using lipofectamine 2000 (catalog \#11668-019; Invitrogen) or Nucleofector kit V (catalog \#VCO-1001; Amaxa, Gaithersburg, MD) according to the manufacturer's instructions. Cells were switched to the DM $24 \mathrm{~h}$ later.

Protein interaction assays. Yeast two hybridization was performed as described previously (Huang et al., 2000). To assay the direct interaction, $\left[{ }^{35} \mathrm{~S}\right]$-labeled $\beta$-catenin was generated by in vitro translation using the T7/SP6 Coupled Reticulocyte Lysate System (Promega, Madison, WI) and incubated with GST-rapsyn. Bound $\beta$-catenin was visualized by autoradiogram (Luo et al., 2002).

Isolation of surface AChR and its associated proteins. Live myotubes were incubated with $300 \mathrm{~nm}$ soluble biotinylated $\alpha$-bungarotoxin (biotin- $\alpha$ BTX) for $2 \mathrm{~h}$ at $4^{\circ} \mathrm{C}$. After washing, cells were lysed in the extraction buffer containing 0.5\% Lubrol-PX, $75 \mathrm{~mm} \mathrm{KCl,} 50 \mathrm{~mm}$ Tris$\mathrm{HCl}, \mathrm{pH}$ 7.4, 2 mM CaCl$, 4 \mathrm{~mm} \mathrm{MgCl}_{2}, 20 \%$ glycerol, and $1 \mathrm{~mm}$ DTT. Lysates were incubated with streptavidin-coupled agarose beads (Invitrogen) for $6 \mathrm{~h}$ at $4^{\circ} \mathrm{C}$ and washed extensively with the extraction buffer, except Lubrol-PX was $0.1 \%$. Beads-associated proteins were subjected to immunoblotting.

AChR cluster assays. C2C12 cells plated on coverslips were transfected with or without indicated constructs. Fully differentiated myotubes were treated with agrin $(\mathrm{C} 4,8)$ to induce AChR clusters (Luo et al., 2002). After fixation in $2 \%$ paraformaldehyde for $30 \mathrm{~min}$, cells were incubated with 50 nM rhodamine-conjugated $\alpha$-bungarotoxin (R-BTX) (Invitrogen) for 60 min to label AChR. Coverslips were mounted in VectaSheild (Vector Laboratories, Burlingame, CA) and viewed under a Zeiss (Thornwood, NY) epifluoresence microscope. Images were collected with Axiovision 3.1 software. AChR clusters with diameters or a longer axis $\geq 4 \mu \mathrm{m}$ were scored.

\section{Results}

$\boldsymbol{\beta}$-Catenin associates with the AChR complex through rapsyn

To understand mechanisms of how rapsyn mediates AChR clustering, we screened for rapsyn-interacting proteins by yeast twohybrid screens and identified $\beta$-catenin using full-length rapsyn as bait (Z. Hall, personal communication). The interaction between $\beta$-catenin and rapsyn was specific because rapsyn did not bind to the intracellular domain of ErbB4, an irrelevant kinase and various control proteins (data not shown). To determine whether rapsyn interacts directly with $\beta$-catenin, not via a third component, and to identify the domain in $\beta$-catenin necessary for binding, recombinant $\beta$-catenin proteins were generated by in vitro translation. $\left[{ }^{35} \mathrm{~S}\right]$-labeled proteins were incubated with GST-rapsyn immobilized on agarose beads. GST-rapsyn, but not GST alone, bound to $\beta$-catenin (Fig. $1 A$ ). The $\mathrm{C}$-terminal region (amino acids 474-781) including armadillo domains 9-12 did not bind to $\beta$-catenin; nor did the armadillo domains $5-9$, suggesting that the interacting domain for rapsyn is localized in the $\mathrm{N}$-terminal region (Fig. $1 \mathrm{~A}$, right). In agreement, a recombinant protein containing armadillo domains $1-4$ was sufficient to interact with rapsyn (Fig. $1 A, B$ ). Thus $\beta$-catenin interacts directly with rapsyn via armadillo domains $1-4$. 
Because rapsyn is associated with AChRs, we reasoned that via interacting with rapsyn, $\beta$-catenin may be in the AChR complex in muscle cells. To test this hypothesis, live $\mathrm{C} 2 \mathrm{C} 12$ myotubes were incubated with biotin- $\alpha$ BTX to label surface AChRs, which were then isolated by streptavidin-coupled agarose beads. AChRs and associated proteins were revealed by immunoblotting with antibodies against the $\operatorname{AChR} \alpha$, rapsyn, and $\beta$-catenin. As shown in Figure $1 C$, rapsyn was detectable in the AChR complex, and such interaction was increased by agrin, indicating that agrin regulates the rapsynAChR interaction in agreement with a previous report (Moransard et al., 2003). Interestingly, $\beta$-catenin coprecipitated with biotinylated AChRs, suggesting that it associates with the AChR complex. Such association appeared to be specific because it did not occur with streptavidinagarose beads or Sepharose 4B beads incubated with biotinylated lysates (data not shown). Moreover, the $\beta$-catenin-AChR association was increased by agrin, in a time course similar to that of the rapsynAChR interaction, suggesting that the interaction may be stimulated by agrin.

We next determined whether $\beta$-catenin association to the AChR complex requires rapsyn. Muscle cells derived from rapsyn ${ }^{-1-}$ mice (clone 11-7) are deficient in rapsyn and do not form AChR clusters in response to agrin (Apel et al., 1997; Fuhrer et al., 1999). As shown in Figure $1 D$, rapsyn as well as $\beta$-catenin became associated with the AChR complex in agrin-stimulated control muscle cells (clone 12-10) derived from heterozygous littermates. In contrast, however, $\beta$-catenin was barely detectable in the AChR complex in rapsyn ${ }^{-1-}$ myotubes (Fig. $1 D$ ). Note that the amounts of $\beta$-catenin were similar in control and rapsyn ${ }^{-1-}$ myotube lysates. These results demonstrate the dependence of the $\beta$-catenin-AChR association on rapsyn, suggesting that rapsyn may recruit $\beta$-catenin to the AChR complex in a manner that can be regulated by agrin. Immunohistochemical analysis showed that $\beta$-catenin was enriched at the NMJ but also present in the sarcolemma of muscle fibers (data not shown).

\section{Suppression of $\boldsymbol{\beta}$-catenin expression reduced AChR clusters in agrin-stimulated muscle cells}

To determine whether $\beta$-catenin plays a role in AChR clustering, a DNA-based shRNA approach was used to suppress $\beta$-catenin expression in $\mathrm{C} 2 \mathrm{C} 12$ muscle cells. Three shRNA- $\beta$-catenin constructs were tested for effectiveness to inhibit $\beta$-catenin expression (Fig. $2 A$ ). shRNA- $\beta$-Cat811 (shRNA-811) was most effective in inhibiting expression of cotransfected $\beta$-catenin in COS cells, followed by shRNA-1196 and shRNA-2405. As a control, a shRNA construct containing the scrambled sequence had no effect. Moreover, shRNA-811 and shRNA-1196 had no effect on expression of rapsyn (Fig. $2 \mathrm{~B}$ ). To further demonstrate the specificity of the shRNA constructs, we generated GFP-RF811 and
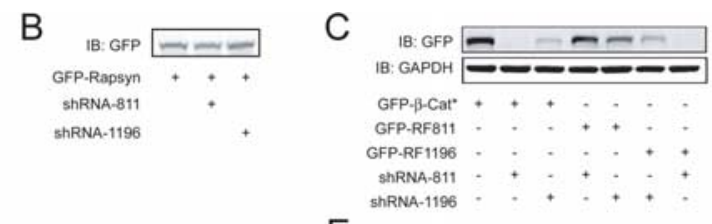

$\mathrm{E}$
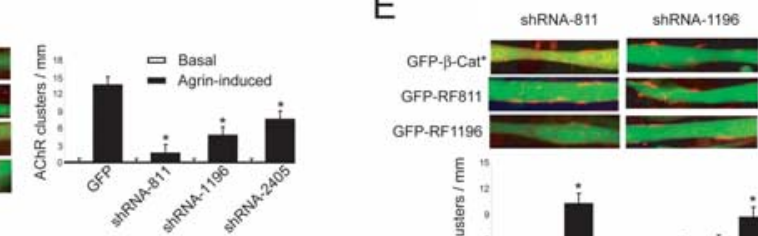

GFP-RF 199
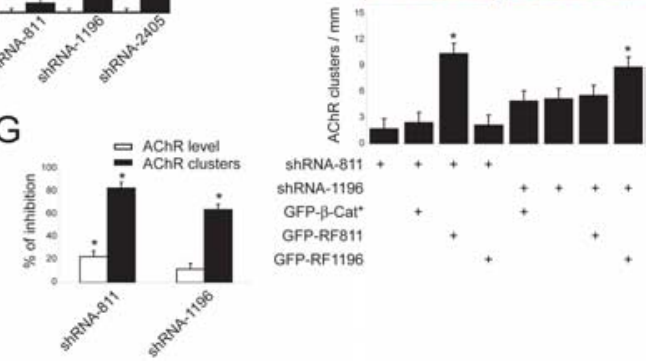

Figure 2. $\quad \beta$-Catenin is required for agrin-induced $A C h R$ clusters. $A, B, \beta$-Catenin shRNAs suppress expression of $\beta$-catenin but not rapsyn. COS7 cells were cotransfected with stable GFP- $\beta$-catenin (GFP- $\beta$-cat $\left.{ }^{*}\right)(\boldsymbol{A})$ or GFP-rapsyn $(\boldsymbol{B})$ with $\beta$-catenin shRNA-1196, -2405, or control shRNA-scramble. Lysates of transfectants were subjected to immunoblotting using anti-GFP antiinmoblotting using antibodies against GFP and glyceraldehyde-3-phosphate dehydrogenase (GAPDH). D, Agrin-induced AChR

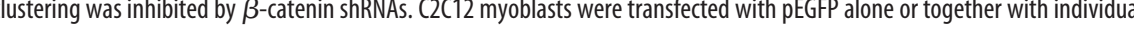

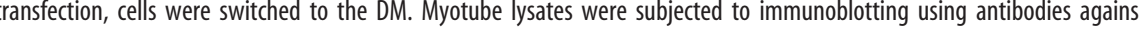
$\beta$-catenin and AChR $\alpha$. Band density was analyzed by NIH Image. Data shown in the histograms are mean \pm SEM with control as $100 \%(n=3)$. G, Comparison of $\beta$-catenin shRNA effects on AChR levels and clusters. Data on AChR levels are from $\boldsymbol{F}$, whereas data on $A C h R$ clusters are from $\boldsymbol{D}$. All quantitative data are shown as mean \pm SEM. ${ }^{*} p<0.01$. IB, Immunoblotting.

GFP-RF1196 that had silent mutations (without changing the amino acid sequence) that avoid targeting by respective shRNAs. As shown in Figure 2C, expression of GFP-RF811 and GFPRF1196 could not suppressed by shRNA-811 and shRNA-1196, respectively. These results suggest that the shRNA constructs inhibit expression of $\beta$-catenin via specific targeting sequences. Next, shRNA constructs were introduced into C2C12 myoblasts together with a plasmid encoding enhanced GFP (pEGFP) to label transfected cells. Resulting myotubes were stained with R-BTX and analyzed for AChR clusters in response to agrin. Agrin induced AChR clusters in control pEGFP-expressing myotubes (Fig. 2D). In contrast, the number of clusters was reduced in myotubes cotransfected with shRNA- $\beta$-catenin constructs. The inhibitory effect correlated positively with that on $\beta$-catenin expression, with shRNA-811 being most potent, followed by shRNA-1196 and shRNA-2405 (Fig. 2A,D). Notably, the inhibitory effect of $\beta$-catenin shRNAs on AChR clustering was rescued by respective refractory $\beta$-catenin mutants (Fig. $2 E$ ).

To determine whether the reduction in AChR clusters was attributable to possible changes in AChR expression, $\mathrm{C} 2 \mathrm{C} 12$ myoblasts were transfected by a nucleofection method with high efficiency. As shown in Figure 2F, shRNA-1196 reduced $\beta$-catenin expression but had little effect on AChR levels. However, shRNA-811, which was more potent in inhibiting $\beta$-catenin expression, caused a mild but significant decrease in AChR levels. 

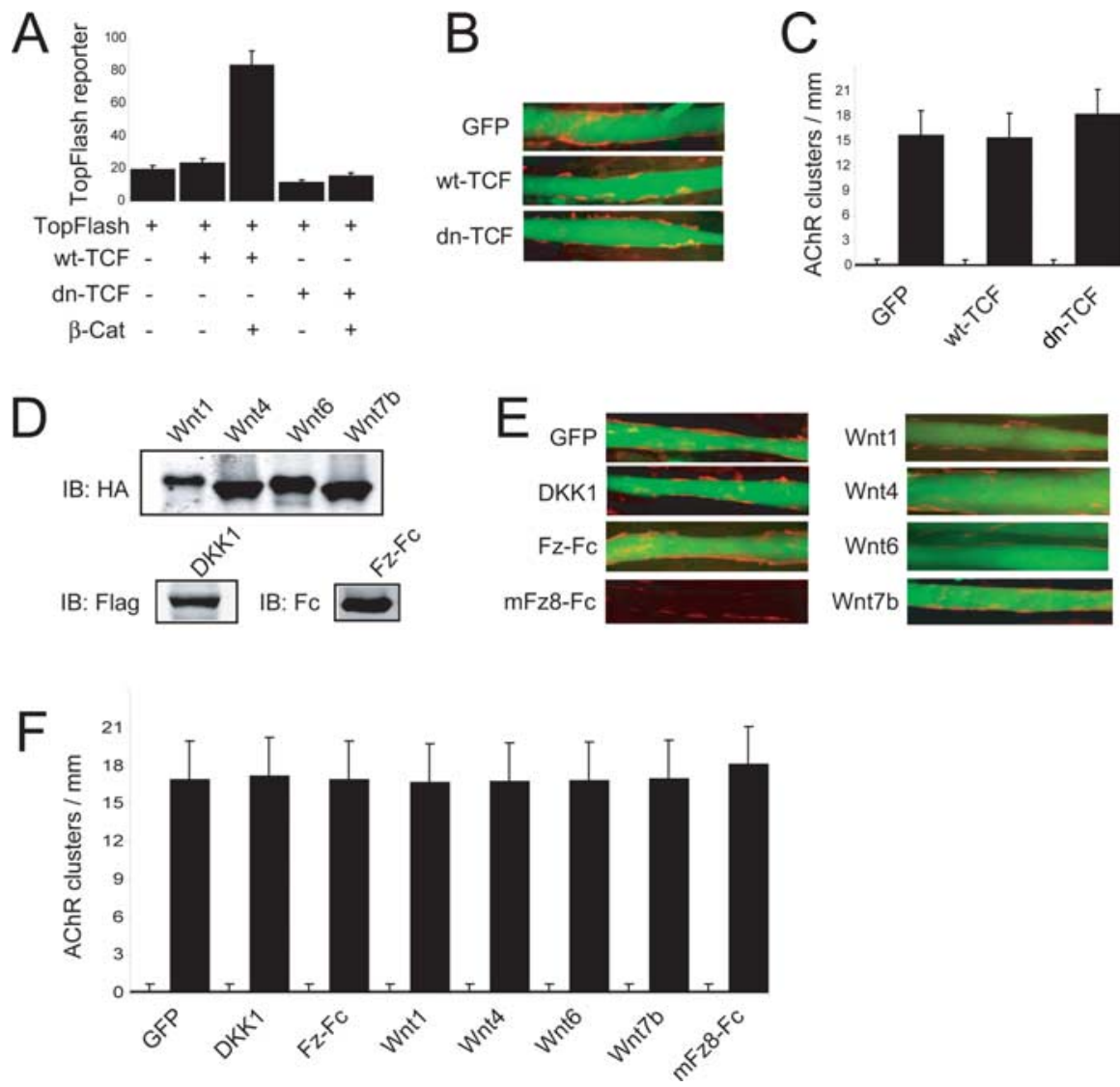

Figure 3. $\beta$-Catenin transcription activity is dispensable in regulation of AChR clustering. $\boldsymbol{A}$, Inhibition of TopFlash reporter activity by dn-TCF4. COS7 cells were transfected with TopFlash with or without $\beta$-catenin and wild-type (wt)- or dn-TCF. pRL-TK was cotransfected as control of transfection efficiency and sample handling. The ratio was 10:10:1 for TopFlash:TCF contructs:pRLTK. Relative luciferase activities (firefly/Renila; mean \pm SEM) from a representative experiment in duplicates, which was repeated three times with similar results, are shown. $\boldsymbol{B}$, Normal agrin-induced AChR clusters in $\mathrm{C2}_{2} \mathrm{C} 2$ cells expressing dn-TCF4. $\mathrm{C}_{2} \mathrm{C12}$ myoblasts were transfected with pEGFP, dn-TCF4, or wt-TCF4 in a ratio of 1:20 (pEGFP:TCF4 constructs). AChR clusters were assayed as in Figure 2D. C, Quantitative analysis of data in $\boldsymbol{B}$. Data were shown as mean \pm SEM $(n=30)$. Open bars, Without agrin; filled bars, agrin stimulated. D, Expression of Wnt, DKK, and Fz-Fc constructs in $\mathrm{C}_{2} \mathrm{C} 12$ cells. $\mathrm{C} 2 \mathrm{C} 12$ myoblasts were transfected with pFLAG-DKK1, hlgG-mFz8CRD, pKH3-Wnt1, pKH3-Wnt4, pKH3-Wnt6, or pKH3-Wnt7b. Expression in resulting myotubes was analyzed by immunoblotting with indicated antibodies. $E$, Normal AChR clustering by agrin in $\mathrm{C} 2 \mathrm{C} 12$ cells expressing Wnt signaling molecules. 22 (12 myoblasts were transfected with pEGFP alone or together with indicated constructs in a ration of 1:20. AChR clusters were assayed as in Figure 2 D. $\boldsymbol{F}$, Quantitative analysis of data in $\boldsymbol{B}$. Data were shown as mean $\pm \operatorname{SEM}(n=30)$. Open bars, Without agrin; filled bars, agrin stimulated. IB, Immunoblotting.

These results could suggest a role of $\beta$-catenin in regulating AChR expression. Figure $2 G$ compares the inhibitory effects of the two shRNA constructs on AChR expression and on cluster formation. shRNA-1196 inhibited agrin-induced AChR clustering by $60 \%$ without significantly altering AChR levels. When $\beta$-catenin levels were further reduced by shRNA-811, AChR expression was compromised. Together, these results suggest that $\beta$-catenin may be necessary for agrin-induced AChR aggregation.

\section{T-cell factor transcription activity was dispensable for AChR clustering}

$\beta$-Catenin is a protein with multiple functions (Yap et al., 1997). It serves as a transcription cofactor by interacting with T-cell factor (TCF)/LEF1 to regulate gene expression in the canonical Wnt pathway (Behrens et al., 1996). To investigate whether $\beta$-catenin-mediated transcription is necessary for AChR clustering, we explored the consequence of suppressing the function of TCF/LEF1. The $\mathrm{N}$ terminus of TCF/LEF1 binds to $\beta$-catenin (Molenaar et al., 1996). TCF/LEF1 deletion mutants without the
$\mathrm{N}$ terminus are unable to associate with $\beta$-catenin and thus function as a dominant-negative (dn) mutant (Molenaar et al., 1996). Expression of dnTCF4 blocked $\beta$-catenin induction of the TopFlash reporter (Fig. 3A) (Korinek et al., 1997). However, dn-TCF4 had little effect on basal- or agrin-induced AChR clustering (Fig. $3 B, C$ ), which argues against the involvement of TCF/LEF1mediated transcription in AChR cluster formation.

Several components of the Wnt signaling pathway including Dishevelled (Dvl) and adenomatous polyposis coli (APC) are implicated in AChR cluster formation (Luo et al., 2002; Wang et al., 2003). To investigate whether Wnt signaling is necessary for AChR clustering, we studied effects of Wnt signaling inhibitors and activators on AChR clusters. Wnt signaling can be blocked by overexpression of DKK1 or Frizzled-Fc fusion protein, or by application of the soluble Frizzled-Fc fragment in the medium (Deardorff et al., 1998; Glinka et al., 1998). To determine whether Wnt signaling is necessary for AChR clustering, C2C12 muscle cells were treated with $\mathrm{mFz} 8-\mathrm{Fc}$ or transfected with indicated Wnt agonists and antagonists (Fig. 3D). As shown in Figure 3, E and F, basal- and agrin-induced AChR clusters did not appear to be affected by the treatment or transfection compared with nontreated cells or cells expressing GFP alone. These results are in line with the notion that Wnt signaling may have a limited role in AChR cluster formation.

\section{$\boldsymbol{\beta}$-Catenin regulates $\mathrm{AChR}$ clustering through interaction with $\alpha$-catenin \\ $\beta$-Catenin is a cytoplasmic protein of the adherence complex (Yap et al., 1997). It} binds to the cytoplasmic domain of cadherins, the transmembrane components of the adherens junction, and, at the same time, $\alpha$-catenin to regulate actin cytoskeleton (Drees et al., 2005). In light of the findings that $\beta$-catenin interacts with rapsyn and is necessary for AChR clustering, we hypothesized that $\beta$-catenin may bridge rapsyn to $\alpha$-catenin to regulate actin cytoskeleton. To test this hypothesis, we determined whether $\alpha$-catenin was present in the complex of surface AChRs in C2C12 myotubes. As shown in Figure $4 A$ (left), $\alpha$-catenin was detectable in the AChR complex and, as observed with $\beta$-catenin, the amount of AChRassociated $\alpha$-catenin was increased in C2C12 myotubes stimulated with agrin. Next, we investigated whether the $\beta$-catenin interaction with $\alpha$-catenin is involved in AChR cluster formation. The motif in $\beta$-catenin necessary for interaction with $\alpha$-catenin is mapped to the $\mathrm{N}$-terminal region. Thr-120 and Val122 are two key amino acid residues in $\beta$-catenin to interact with $\alpha$-catenin (Aberle et al., 1996). Mutation of the two residues to alanines (as in $\beta$-catenin-AA) prevents $\beta$-catenin from binding to $\alpha$-catenin (Aberle et al., 1996) (data not shown). As shown in Figure $4 A$, expression of $\beta$-catenin-AA prevented endogenous 

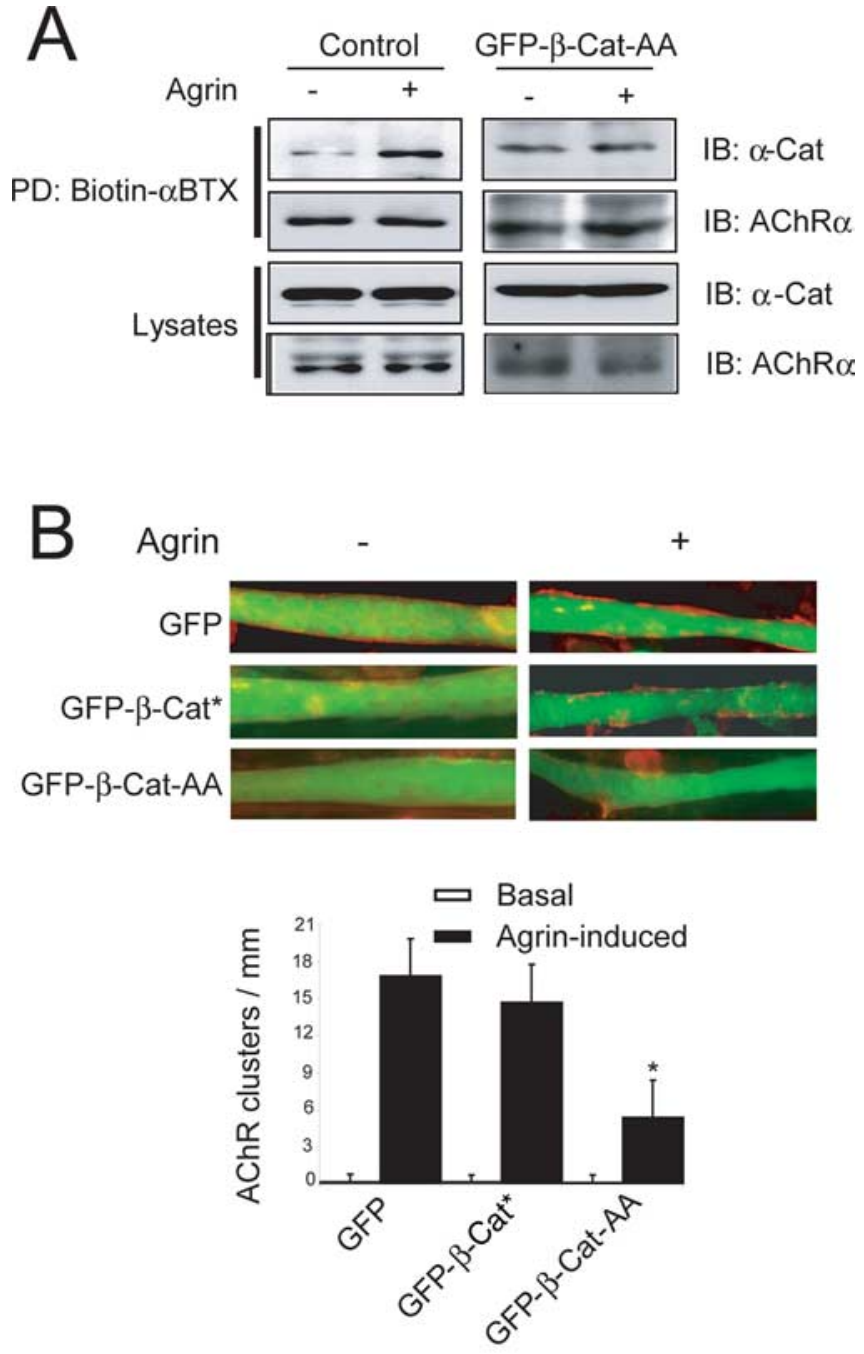

C

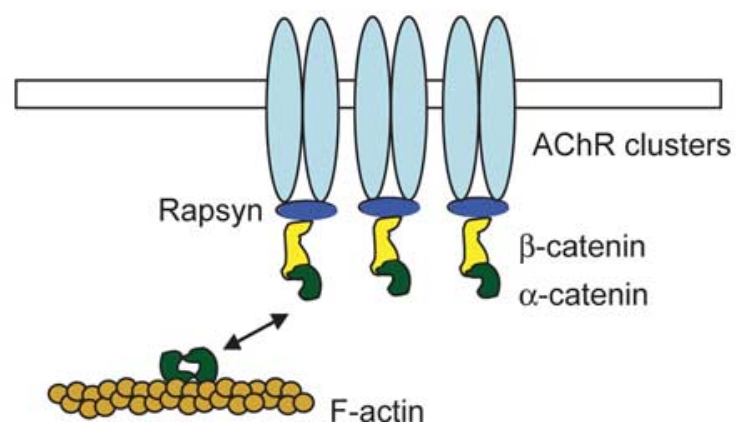

Figure 4. $\beta$-Catenin regulation of $\mathrm{AChR}$ clustering requires interaction with $\alpha$-catenin. $\boldsymbol{A}$, Association of $\alpha$-catenin with surface AChR complex in muscle cells. Surface AChR was labeled and purified from control C2C12 myotubes (left) or those differentiated from cells nucleofected with GFP- $\beta$-catenin-AA (GFP- $\beta$-Cat-AA; right), as described in Figure 1C. AChR-associated proteins were analyzed by immunoblotting with antibodies against $\operatorname{ACh} \alpha \alpha$ and $\alpha$-catenin. Lysates ( $5 \%$ of input) were also subjected to immunoblotting to indicate equal amounts of inputs. $\boldsymbol{B}$, Expression of $\beta$-catenin-AA inhibits AChR clustering. $C 2 C 12$ myoblasts were transfected with GFP- $\beta$-cat ${ }^{*}$ or GFP- $\beta$-Cat-AA. AChR clusters were induced and scored as in Figure $2 D$. Images of representative experiments that were repeated five times with similar results, are shown. Histograms show quantification of AChR clusters (mean $\pm \mathrm{SEM} ; n=30 ;{ }^{*} p<$ 0.01). C, Working model. Via interacting with rapsyn and $\alpha$-catenin, $\beta$-catenin may link the AChR to the cytoskeleton. $\beta$-Catenin may also regulate expression of synaptic proteins including the AChR. PD, Pull down; IB, immunoblotting. $\alpha$-catenin from associating with surface AChRs, even in the presence of agrin, suggesting that $\alpha$-catenin association to the AChR complex was dependent on interacting with $\beta$-catenin. Accordingly, expression of $\beta$-catenin-AA attenuated agrin-stimulated AChR clustering (Fig. $4 B$ ). Together, these results suggest a necessary role of $\alpha$-catenin in AChR clustering, probably by interacting with $\beta$-catenin.

\section{Discussion}

The present study reveals a potentially novel mechanism that regulates AChR cluster formation. First, we showed that $\beta$-catenin interacts directly with rapsyn and thus associates with surface AChR. The association of $\beta$-catenin with AChR is upregulated by agrin. Second, suppression of $\beta$-catenin expression attenuates agrin-induced AChR clustering in muscle cells, suggesting a necessary role in this process. We also demonstrate that AChR clustering does not require the transcription activity of TCF/LEF1 factors. Rather, the interaction of $\beta$-catenin with $\alpha$-catenin appeared to be necessary. These results corroborate that $\beta$-catenin, functioning downstream of rapsyn, is necessary for AChR cluster formation, probably by regulating the cytoskeleton in a manner dependent on $\alpha$-catenin (Fig. $4 C$ ).

Wnt signaling has been shown to mediate or regulate presynaptic and postsynaptic differentiation of glutamatergic NMJs in Drosophila (Hall et al., 2000; Mathew et al., 2005). At mammalian CNS synapses, $\beta$-catenin has been implicated in vesicle localization at presynaptic terminals (Bamji et al., 2003), and neural activity induces the redistribution of $\beta$-catenin into dendritic spines to influence synaptic size and strength (Murase et al., 2002; Yu and Malenka, 2003). Recent studies suggest that Wnt signaling molecules including Dvl and APC may regulate AChR cluster formation. Dvl, an adapter protein downstream of the Wnt receptor Frizzled, acts by interacting with both MuSK and Pak1, whereas APC, a protein that regulates $\beta$-catenin stability, binds to the AChR $\beta$-subunit (Luo et al., 2002; Wang et al., 2003). Moreover, APC may play a role in organizing neuronal AChR clusters in chick ciliary ganglion neurons (Temburni et al., 2004). Together with results of this study, these observations suggest that Wnt signaling components may be involved in mammalian NMJ formation, although the role of each component appears to be distinct from those in classic Wnt pathways.

\section{References}

Aberle H, Schwartz H, Hoschuetzky H, Kemler R (1996) Single amino acid substitutions in proteins of the armadillo gene family abolish their binding to alpha-catenin. J Biol Chem 271:1520-1526.

Apel ED, Glass DJ, Moscoso LM, Yancopoulos GD, Sanes JR (1997) Rapsyn is required for MuSK signaling and recruits synaptic components to a MuSK-containing scaffold. Neuron 18:623-635.

Bamji SX, Shimazu K, Kimes N, Huelsken J, Birchmeier W, Lu B, Reichardt LF (2003) Role of beta-catenin in synaptic vesicle localization and presynaptic assembly. Neuron 40:719-731.

Behrens J, von Kries JP, Kuhl M, Bruhn L, Wedlich D, Grosschedl R, Birchmeier W (1996) Functional interaction of beta-catenin with the transcription factor LEF-1. Nature 382:638-642.

Bloch RJ (1986) Actin at receptor-rich domains of isolated acetylcholine receptor clusters. J Cell Biol 102:1447-1458.

Burden SJ, DePalma RL, Gottesman GS (1983) Crosslinking of proteins in acetylcholine receptor-rich membranes: association between the betasubunit and the $43 \mathrm{kd}$ subsynaptic protein. Cell 35:687-692.

Dai Z, Luo X, Xie H, Peng HB (2000) The actin-driven movement and formation of acetylcholine receptor clusters. J Cell Biol 150:1321-1334.

Deardorff MA, Tan C, Conrad LJ, Klein PS (1998) Frizzled-8 is expressed in the Spemann organizer and plays a role in early morphogenesis. Development 125:2687-2700.

DeChiara TM, Bowen DC, Valenzuela DM, Simmons MV, Poueymirou WT, 
Thomas S, Kinetz E, Compton DL, Rojas E, Park JS, Smith C, DiStefano PS, Glass DJ, Burden SJ, Yancopoulos GD (1996) The receptor tyrosine kinase MuSK is required for neuromuscular junction formation in vivo. Cell 85:501-512.

Drees F, Pokutta S, Yamada S, Nelson WJ, Weis WI (2005) Alpha-catenin is a molecular switch that binds E-cadherin-beta-catenin and regulates actin-filament assembly. Cell 123:903-915.

Fuhrer C, Gautam M, Sugiyama JE, Hall ZW (1999) Roles of rapsyn and agrin in interaction of postsynaptic proteins with acetylcholine receptors. J Neurosci 19:6405-6416.

Gautam M, Noakes PG, Mudd J, Nichol M, Chu GC, Sanes JR, Merlie JP (1995) Failure of postsynaptic specialization to develop at neuromuscular junctions of rapsyn-deficient mice. Nature 377:232-236.

Gautam M, Noakes PG, Moscoso L, Rupp F, Scheller RH, Merlie JP, Sanes JR (1996) Defective neuromuscular synaptogenesis in agrin-deficient mutant mice. Cells 85:525-535.

Glinka A, Wu W, Delius H, Monaghan AP, Blumenstock C, Niehrs C (1998) Dickkopf-1 is a member of a new family of secreted proteins and functions in head induction. Nature 391:357-362.

Hall AC, Lucas FR, Salinas PC (2000) Axonal remodeling and synaptic differentiation in the cerebellum is regulated by WNT-7a signaling. Cell 100:525-535.

Huang YZ, Won S, Ali DW, Wang Q, Tanowitz M, Du QS, Pelkey KA, Yang DJ, Xiong WC, Salter MW, Mei L (2000) Regulation of neuregulin signaling by PSD-95 interacting with ErbB4 at CNS synapses. Neuron 26:443-455.

Korinek V, Barker N, Morin PJ, van Wichen D, de Weger R, Kinzler KW, Vogelstein B, Clevers H (1997) Constitutive transcriptional activation by a beta-catenin-Tcf complex in APC $-/-$ colon carcinoma. Science 275:1784-1787.

LaRochelle WJ, Froehner SC (1986) Determination of the tissue distributions and relative concentrations of the postsynaptic $43-\mathrm{kDa}$ protein and the acetylcholine receptor in Torpedo. J Biol Chem 261:5270-5274.

Luo ZG, Wang Q, Zhou JZ, Wang J, Luo Z, Liu M, He X, Wynshaw-Boris A, Xiong WC, Lu B, Mei L (2002) Regulation of AChR clustering by Dishevelled interacting with MuSK and PAK1. Neuron 35:489-505.

Mathew D, Ataman B, Chen J, Zhang Y, Cumberledge S, Budnik V (2005)
Wingless signaling at synapses is through cleavage and nuclear import of receptor DFrizzled2. Science 310:1344-1347.

McMahan UJ, Horton SE, Werle MJ, Honig LS, Kroger S, Ruegg MA, Escher G (1992) Agrin isoforms and their role in synaptogenesis [review]. Curr Opin Cell Biol 4:869-874.

Molenaar M, van de Wetering M, Oosterwegel M, Peterson-Maduro J, Godsave S, Korinek V, Roose J, Destree O, Clevers H (1996) XTcf-3 transcription factor mediates beta-catenin-induced axis formation in Xenopus embryos. Cell 86:391-399.

Moransard M, Borges LS, Willmann R, Marangi PA, Brenner HR, Ferns MJ, Fuhrer C (2003) Agrin regulates rapsyn interaction with surface acetylcholine receptors, and this underlies cytoskeletal anchoring and clustering. J Biol Chem 278:7350-7359.

Murase S, Mosser E, Schuman EM (2002) Depolarization drives betacatenin into neuronal spines promoting changes in synaptic structure and function. Neuron 35:91-105.

Sanes JR, Lichtman JW (1999) Development of the vetebrate neuromuscular junction. Annu Rev Neurosci 22:389-442.

Semenov MV, Tamai K, Brott BK, Kuhl M, Sokol S, He X (2001) The Wnt antagonist Dickkopf1 is a ligand for low density lipoprotein receptor related proteins. Curr Biol 26:951-961.

Temburni MK, Rosenberg MM, Pathak N, McConnell R, Jacob MH (2004) Neuronal nicotinic synapse assembly requires the adenomatous polyposis coli tumor suppressor protein. J Neurosci 24:6776-6784.

Wang J, Jing Z, Zhang L, Zhou G, Braun J, Yao Y, Wang ZZ (2003) Regulation of acetylcholine receptor clustering by the tumor suppressor APC. Nat Neurosci 6:1017-1018.

Yap AS, Brieher WM, Gumbiner BM (1997) Molecular and functional analysis of cadherin-based adherens junctions. Annu Rev Cell Dev Biol 13:119-146.

Yu X, Malenka RC (2003) Beta-catenin is critical for dendritic morphogenesis. Nat Neurosci 6:1169-1177.

Zhang W, Chen X, Kato Y, Evans PM, Yuan S, Yang J, Rychahou PG, Yang VW, He X, Evers BM, Liu C (2006) Novel cross talk of Kruppel-like factor 4 and $\{$ beta\}-catenin regulates normal intestinal homeostasis and tumor repression. Mol Cell Biol 26:2055-2064. 